\title{
8
}
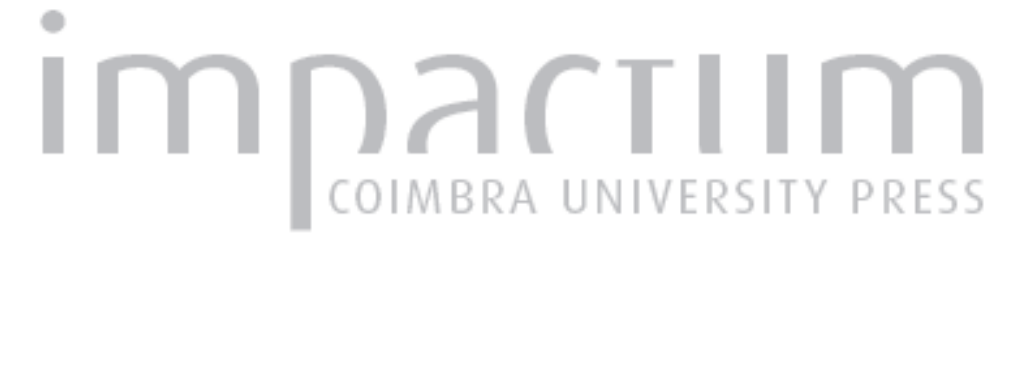

\section{Constituição, política e esperança: o dilema da efetivação constitucional sem a política}

\author{
Autor(es): $\quad$ Lima, Martonio Mont'Alverne Barreto; Almeida, Plínio Régis Baima de \\ Publicado por: Universidade Católica de Petrópolis \\ URL \\ persistente: \\ URl:http://hdl.handle.net/10316.2/33834 \\ DOI: \\ DOI:http://dx.doi.org/10.14195/2175-0947_2-2_4 \\ Accessed : $\quad$ 26-Apr-2023 03:08:19
}

A navegação consulta e descarregamento dos títulos inseridos nas Bibliotecas Digitais UC Digitalis, UC Pombalina e UC Impactum, pressupõem a aceitação plena e sem reservas dos Termos e Condições de Uso destas Bibliotecas Digitais, disponíveis em https://digitalis.uc.pt/pt-pt/termos.

Conforme exposto nos referidos Termos e Condições de Uso, o descarregamento de títulos de acesso restrito requer uma licença válida de autorização devendo o utilizador aceder ao(s) documento(s) a partir de um endereço de IP da instituição detentora da supramencionada licença.

Ao utilizador é apenas permitido o descarregamento para uso pessoal, pelo que o emprego do(s) título(s) descarregado(s) para outro fim, designadamente comercial, carece de autorização do respetivo autor ou editor da obra.

Na medida em que todas as obras da UC Digitalis se encontram protegidas pelo Código do Direito de Autor e Direitos Conexos e demais legislação aplicável, toda a cópia, parcial ou total, deste documento, nos casos em que é legalmente admitida, deverá conter ou fazer-se acompanhar por este aviso.

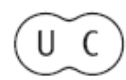



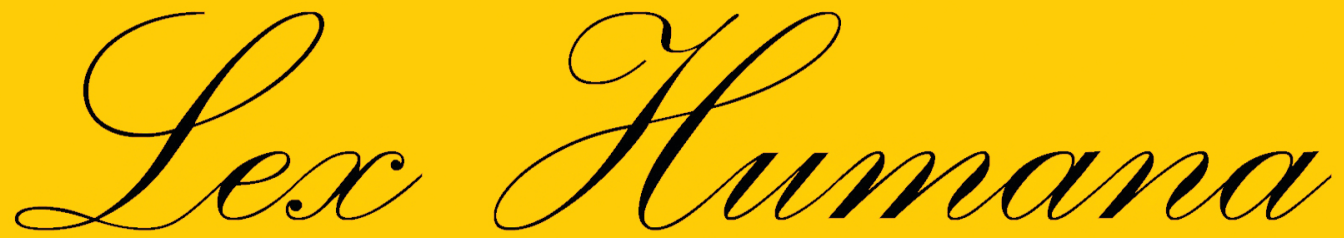

Revista do Programa de Pós-Graduação em Direito da UCP

ISSN(e) 2175-0947

Universidade Católica de Petrópolis Rua Benjamin Constant, 213 - Petrópolis - Centro CEP 25610-130

Tel: (24) 2244-4000 E-mail: lexhumana@ucp.br 


\section{Constituição, Política e Esperança - O Dilema da EfetivaçÃo Constitucional SEM A POLÍTICA}

Martonio Mont'Alverne Barreto Lima. Plínio Régis Baima de Almeida ${ }^{1}$.

Resumo: De origem pós Segunda Guerra Mundial, e a exemplo do pensamento comum que vem condicionando parte importante de setores da sociedade, o neoconstitucionalismo ingressa no campo de reflexão conformativa da Constituição Federal de 1988. De base liberal, mais pautada nos teóricos estadunidenses, o neoconstitucionalismo desacredita o texto constitucional na medida em que atribui a tarefa de efetivação constitucional a intérpretes, lingüistas e a ponderações. Impõe-se, dessa forma, reflexão a essa visão, tendo-se como substratos indutivos elementos reais de conformação constitucional, que não sejam simples interpretações normativas, como é o caso da cultura, da história, das artes e da política.

Palavras-chave: Neoconstitucionalismo; política; efetivação constitucional; dirigismo constitucional.

Abstract: With its origins after 2nd World War, the "neoconstitutionalism" movement has established itself as an

1 Martonio Mont'Alverne Barreto Lima é Doutor e Pós-Doutor em Direito pela Universidade de Frankfurt, Professor da Universidade de Fortaleza e Procurador-Geral do Município de Fortaleza. Email: barreto@unifor.br. Plínio Régis Baima de Oliveira é pesquisador e Procurador do Estado do Amapá. Email: pliniobaima@hotmail.com. 
important chain of thinking, characterized by a formal reading of any constitution. In this meaning, interpretation, internal aspects of a constitutional text, equilibrium among words and constitutional ideas would be enough to give life to any constitution. Strong in the United States of America and in same Europeans countries, the "neo constitutionalism" takes distance from culture, history and politics, which, in this article, are considered necessary to a constitutional success.

Keywords: Neo-constitutionalism, politics, constitutional reality, social constitutionalism.

Mas é exatamente neste compromisso, nesta "abertura" da Constituição de Weimar que reside, para [Hermann] Heller, seu fundamento politico, de possibilidade livre, para resolver em processos democráticos os conflitos sociais e politicos ${ }^{2}$.

As palavras acima foram proferidas em favor de Hermann Heller, teórico do constitucionalismo e do Estado durante seus estudos sobre a natureza da Constituição de Weimar de 1919. Heller, assim como tantos outros, viu esta mesma Constituição cair vítima do nazismo germânico, com as monstruosas conseqüências que

2 STAFF, Ilse. Staatslehre in der Weimarer Republick, erste Auflage, Suhrkamp, Frankfurt/M., 1985, p.8. No original:"Aber gerade im diesem Kompromiß, in dieser $>$ Offenheit $<$ der Weimarer Reichsverfassung liegt für Heller ihre politische Grundentscheidung, nämlich die > freie Möglichkeit $<$, im demokratischen Verfahren die politischen und sozialen Konflikte zu lösen“". 
a história tem registrado. $\mathrm{O}$ que desejamos salientar nesta breve introdução é mostrar como a reflexão que inclui história e política no direito constitucional é necessária, não se resumindo a um simples exercício de diletantismo ou refinamento.

Aliada à própria noção metodológica de análise do concreto, submeter a normatividade constitucional aos conflitos concretos de qualquer sociedade é mais que simplesmente realizar uma tarefa científica ou de difícil escolha entre metidos a investigação: é procurar dar vida à constituição para que se compreenda a nova vida que ela, constituição, intenciona operacionalizar na sociedade que pretende governar. Hermann Heller e outros procuraram ver também no dirigismo constitucional a presença da tensão política. Para estes, democratas de primeira hora, não haveria alternativa para uma Alemanha arrasada pela Primeira Guerra Mundial, e aos teóricos do direito não assistia a possibilidade de se furtarem a este debate, tendo como ponto de partida os desafios de uma sociedade desigual, humilhada, sem experiência democrática endógena, onde quase tudo ainda estava por se fazer.

São necessárias, portanto, reflexões sobre o constitucionalismo brasileiro, com o objetivo de se evitar que não fuja de seu papel de contribuir para a maturação democrática e dirigente, impostas pela Constituição Federal em 1988, reconhecendo, sobretudo, que não estamos sozinhos: arte, cultural, história e política serão apenas algumas das ferramentas a que recorremos, se é que somos sinceros o suficiente para não trair nosso compromisso constituinte.

A compreensão de um objeto sujeito à análise epistemológica 
enseja naturais indagações a respeito da formação dos elementos que o compõe, acarretando, por conseguinte, distintas versões sobre o objeto estudado. Significa dizer, por óbvio, que a leitura intelectiva do objeto dependerá da qualificação dos elementos que o compõe para tornar-se apropriada ao caso real. Este breve e manifesto raciocínio se perderia no vazio não fosse a razão que lhe sucede neste trabalho: a reflexão crítica sobre o modelo hermenêutico atual aplicado na compreensão e concretização da Constituição Federal brasileira, ao analisar-se o nível de coerência material entre a interpretação constitucional modista "pós-moderna", que muitos denominam de "neconstitucionalismo", e a interinfluência de realidades que orbitam fora da esfera interna do texto constitucional.

A dificuldade em estabelecer limites à participação dos sujeitos sociais, na defesa de direitos essenciais à paz e ao convívio sadio dos povos, estimulou a discussão sobre um modelo normativo que tornasse empiricamente viável a relação entre Estado e administrados e entre estes. Diversos foram os elementos relevados: legitimidade do intérprete, parâmetro para o controle das normas, abrangência das normas, hierarquia, imperatividade, etc. Da origem do constitucionalismo à atualidade, diversas foram as teorias constitucionais que, fundamentadas em bases diferentes de formulação teórica, buscaram encontrar um modelo ideal que legitimasse o texto constitucional frente à realidade social.

De Carl Schmidt a Konrad Hesse, de Kelsen a Lassale, de Canotilho a Paulo Bonavides; a constatação de certo "utilitarismo constitucional" em momentos importantes da história, como é o caso da Alemanha de Hitler, conduziu a um debate ainda inacabado na Teoria Constitucional a respeito do modelo ideal de interpretação constitucional. No percurso destes autores, constatou-se uma dicotomia que ainda hoje desafia intelectuais do direito e da política, 
uma vez que direito e política, por mais que se insista no contrário, andam de braços dados em qualquer realidade constitucional.

A dicotomia a que nos referimos é aquela traduzida pela presença do Estado, seus nexos com a sociedade, a intensidade e o tamanho desta atuação. No limite desta discussão, o idealismo constitucional, dissociado do realismo, em especial no que envolve as análises sobre a sociedade brasileira, tem sido a ferramenta predileta do neoconstitucionalismo normativista, que enxerga na autonomia normativa da Constituição Federal os elementos suficientes à efetivação de todos os direitos e garantias constitucionais, como se, por exemplo, arte, cultura, história, política etc. não integrassem o universo da obseração jurídica ou como se fosse possível compreender mesmo a realidade normativa constitucional sem tais elementos.

Em meio a dificuldades materiais de efetivação do texto constitucional demonstradas pelo acúmulo histórico, o discurso legalista tornou-se letalmente sedutor àqueles que preferem não enfrentar as contingências que a vida política impõe. Alheio aos conflitos reais, tanto durante o exercício constituinte como durante a realidade que a sucede, o idealismo legal acaba por persuadir jogando com a ansiedade e a imaturidade em reconhecer a dimensão da história do homem e a fugacidade do momento histórico que uma vida humana pode abarcar - ao seu modelo de efetivação constitucional, longe do confronto com a dimensão real; mais perto do campo sedutor do discurso.

Constatada a condição afeta ao Constitucionalismo atual, cabe-nos confrontá-la às tensões que induzem e conduzem o processo histórico, em busca de uma interpretação "integralizante" do texto constitucional como resposta ao pensamento linear do idealismo legal. A advertência de Schopenhauer ao perigo do pensamento "erudito" 
nos serve como contra-senso inspirador: " ... a verdadeira formação para a humanidade exige universalidade e uma visão geral"3. A idéia sinaliza para a necessidade de se pensar organicamente, levando-se em conta todos os elementos que compõe e traduzem a realidade e, no caso objeto deste trabalho, um modelo constitucional universal, mais próximo dos diversos fatores que contribuíram para a "solução" constituinte, bem como o complexo contexto sobre o qual se encontra inserida a Constituição, com ele se confundindo em alguns momentos.

O constitucionalismo surgiu como forte resposta ao legado do "fundamentalismo" normativo da monarquia, encontrando guarida teórica no pensamento filosófico iluminista. O modelo constitucional caiu como uma luva aos interesses da classe burguesa, tornando a atuação real do "Estado fictício" - então recém fundado em sua concepção moderna - limitada a normas escritas. Bem verdade que a constituição escrita trouxe benesses a outros setores da sociedade, principalmente no que se refere aos direitos relacionados à liberdade. Não menos verdade, não obstante, é que esse "liberalismo" beneficiava especificamente a classe emergente burguesa e era por ela bastante estimulado e impulsionado. Assim é que, a separação de poderes, construção teórica base do liberalismo, divide o poder porque enfraquece também o Estado em favor da riqueza e da propriedade. A separação de poderes, antes de mais nada, é um dos instrumentos dos ricos, dos proprietários que, sim,seriam os únicos a se preocuparem com os destinos da nação ${ }^{4}$.

Pretende-se, com essa afirmação, desviar-se do foco da visão contratual idealista sobre o papel "puritano" exercido pelo constitucionalismo moderno, direcionando sua importância,

3 SCHOPENHAUER, Arthur. A Arte de escrever, p. 31.

4 Cf.. Domenico Losurdo: Democracia ou Bonapartismo, pp. 104ss. Ainda: Physics and Politics or Thoughts on the Application of the Principles of Natural Selection and the 'Inheritance' to Political Society, 1872, London, pp. 93ss. 
no momento histórico em apreço, ao seu principal "cliente": a classe burguesa. Mostra-se, sob a ótica mais constrita e "real" do materialismo, que até mesmo o constitucionalismo possui seu lado "utilitarista" - muitas vezes não universal como se quer pensar - forçado ao esquecimento no decorrer do processo de alienação e conseqüente "iconização" do texto constitucional. Não se trata de revelar um aspecto negativo do constitucionalismo, mas apenas o de relatar um elemento histórico renegado pelos idealistas.

Fácil perceber a adaptação discursiva que aqui se revela quando se tem em mente as constituições que sucederam a Revolução Francesa de 1789. Como resposta ao monarquismo absolutista, uma constituição fora produzida para rechaçar de vez o dogmatismo monárquico a impregnar o arcabouço normativo francês. Na Constituição de 1791 - a primeira constituição pós revolução - os direitos de natureza "fundamental" eram expostos com imenso orgulho pelos revolucionários; fato que não desautoriza relembrar a visível desarmonia entre as reivindicações no calor da revolução e o texto "morno" feito "nos salões da burguesia francesa". " A liberdade de 1789 respeita a homens abstratos e apolíticos. O verdadeiro homem é aceito sob a forma do indivíduo egoísta. São liberdades formais, sem garantias materiais" ${ }^{5}$.

O texto constitucional francês, a exemplo, garantia ao indivíduo até mesmo o direito de resistência à opressão "como um direito natural e imprescindível do homem" ${ }^{\prime}$, como se pode constatar com a citação do artigo $2^{\circ}$ da Declaração dos Direitos do Homem e do Cidadão de 1789: 'A finalidade de toda associação é a conservação dos direitos naturais e imprescindíveis do homem; esse direitos são

$5 \quad$ GRAU, Eros. Realismo e utopia constitucional, p. 138.

6 COSTA, Nelson Nery. Teoria e Realidade da Desobediência Civil. Editora Forense. Rio de Janeiro, 2a Edição, 2000, pág. 26. 
a liberdade, a segurança e a resistência à opressão. ${ }^{7}$ (grifo nosso) A Declaração dos Direitos do Homem adotada em 29 de maio de 1791 pela Convenção Nacional Francesa reconhecia o direito de resistência, no entanto, " com a votação da Declaração pela Convenção, em 23 de junho de 1793, e publicada como preâmbulo da Constituição de 24 de junho do mesmo ano, já não traz a resistência à opressão enumerada entre os direitos fundamentais" 8 . Esse processo de "domesticação" constitucional teve continuidade ainda na mesma década da primeira constituição francesa9 .

Entre reformas e publicações de novas constituições, a participação popular, doravante bandeira incondicional entre os revolucionários, transforma-se em objeto de adaptação política ${ }^{10}$. "Méritos" e qualidades antes imprescindíveis para a consolidação da revolução passaram, com a vitória, a "deméritos". O desequilíbrio necessário para desestabilizar a monarquia francesa já não era bemvindo na condução do estado, que necessitava, agora, de "paz social" para impor os valores do ideário burguês e por em prática a realização de suas necessidades materiais.

Era urgente e necessário o equilíbrio social para a condução

\begin{tabular}{ll}
\hline 7 & Id. ib, p. 26. \\
8 & Id. ib, p. 27.
\end{tabular}

9 Essa afirmação joga para o campo da retórica a discussão sobre a previsão ou não da desobediência civil em textos constitucionais. Muito se debruçava sobre essa previsão na Constituição de Weimar de 1919, não se chegando a um consenso.

10 A idéia de povo, assim como a de participação popular, intrinsecamente a ela relacionada, padeceu do mesmo mal, sendo igualmente vítima de manipulações. Nesse sentido é a denúncia de Paulo Albuquerque e Plínio Baima: “O 'povo' é invocado nas constituições, mas os textos, e sobretudo a doutrina constitucional, desconstituem-no como agente transformador, limitando a atuação do poder constituinte através de interpretações dirigidas do texto constitucional (ALBUQUERQUE, Paulo e ALMEIDA, Plínio. Metamorfoses da democracia e controle Normativo da Constituição, p. 97).. Friedrich Müller refere-se a essa questão quando observa que "ela (constituição) fala, mas não sobre o poder do povo; ela se atribui legitimidade. Ao mesmo tempo silencia sobre o fato de que essa atribuição não alcança a realidade". Trata-se, portanto, também de um uso mitificador do conceito de povo, na medida em que este passa a ser objeto de adaptação discursiva às injunções do cenário político, de acordo com a correlação de forças dominantes" (MÜLLER, Friedrich, Quem é o povo, p. 50). 
do novo estado. Esse equilíbrio foi buscado no "fiel" dos textos legais. Longe de se conceber como coincidência, o "evolucionismo" normativo acompanhou as necessidades das classes políticas dominantes, cada uma a seu tempo, demonstrando, diferente de qualquer pretensão determinista, que a história das sociedades se conduz por um processo racionalizado, de cuja lógica visualiza-se a estreita ligação entre estado e elite política.

Como remédio aos resquícios do velho estado eàs "inflamadas" reivindicações dos atores políticos revolucionários, a nova classe se abraça às leis. A palavra escrita e devidamente codificada tornase imperativa, a "última e mais nova palavra" do controle social. A sedimentação do individualismo encontra seu forte aliado nos códigos da "era" napoleônica. Tem-se, portanto, a formação do positivismo jurídico excludente, cuja filosofia finca suas bases na concepção unívoca da interpretação dogmática, desconhecendo toda e qualquer interpretação que fuja aos limites dos textos legais.

Na realidade jurídica da dogmática lógico-formal positivista, o reconhecimento de direitos passa obrigatoriamente por um processo de institucionalização de ordem estatal. Como é de amplo conhecimento, estaéa posição dos positivistas em relação ao monopólio estatal do direito. Importante salientar que este posicionamento dos positivistas nada tem, aprioristicamente, de conservadora, na medida em que busca solidificar a autoridade do estado sobre poderes privados concorrentes: econômico e político. E, demais, a gênese do constitucionalismo dirigente ${ }^{11}$, defendida por setores não liberais das sociedades, em especial após a Primeira Guerra Mundial, enxergou na positivação do dirigismo constitucional preciosa ferramenta a garantir tanto a intervenção do estado no domínio econômico, na

11 Cf. LERCHE, Peter. Übermaß und Verfassungsrecht: Zur Bildung des Gesetzgebers and die Grundsätze der Vehältnissmäßigkeit und der Erförderlichkeit, pp. 61ss. 
busca de equilíbrio na distribuição da renda e da riqueza, como na integração à cena política de minorias que não tinham como se deixar representar ou sequer de afirmar sua presença nas representações institucionais, como os parlamentos.

Por outro lado - e este, sim, é o permanente desafio para os positivistas - não há como negar que a normatização de condutas que se realiza fora do estado e é amplamente assimilada por sociedade, e, não raro, pelo próprio estado, pode ingressar no âmbito da validade. Não porque esta normatização venha a violar o estado, mas porque possui um elemento de complementaridade, uma vez que inexiste legislação que preveja todas as formas possíveis da conduta humana. Dessa forma o "estado do Direito" não se distinguiria da ordem jurídica que o organiza, e ao intérprete caberia trucidar todo seu conhecimento e sensibilidade em nome de um ratio legis embebido na seiva do dogmatismo jurídico, conforme nota Goyard-Fabre quando afirma que ${ }^{12}$ :

Ninguém melhor do que Kelsen soube mostrar em sua "teoria pura do direito" que o estado moderno não se distingue da ordem jurídica que o organiza. Esse ponto é capital. Opondo-se a G. Jellinek, Kelsen considera que estado e direito são inseparáveis, a ponto de um estado de nãodireito ser pura contradição nos termos: num estado (status) de não-direito, não pode haver nem estado (Civitas) nem política (politeia). (...) Longe de se limitar a uma teoria descritiva do estado, ele (Kelsen) abala uma tradição secular e define o estado como uma entidade jurídica, ao 
ponto de, para ele, estado e ordem jurídica serem expressões sinônimas.

Ao analisar o papel e definir o conceito de lei no estado de direito liberal, Nuno Piçarra chega a conclusão semelhante a de Fabre em torno da concepção lógico-formal pretendida por Kelsen, ao afirmar que "a lei torna-se a única fonte de Direito: não existe Direito antes de a vontade do legislador o criar"13.

Essa tradição simplificadora da interpretação jurídica, traço do monismo jurídico, ${ }^{14}$ ingressou em uma crise de identidade a partir dos anos de 1960 e 1970, por não mais responder a contento aos problemas emergentes e aos anseios da sociedade. A história oferecenos exemplos em que o estado de Direito invocado em sua concepção lógico-formal destoou abruptamente dos reais movimentos da vida política e social. O estado nacional-socialista de Hitler, a exemplo caricatural, prestou-se a tal papel, cuja "juridicidade pura se transformou em ajuridicidade"15.

A crença da dogmática positivista na estabilidade ou mesmo na imutabilidade da lei, atribuindo tal fato às suas características

13 KELSEN, Hans, Teoria pura do direito, p. 159.

14 Antônio C. Wolkmer aponta quatro grandes ciclos do monismo jurídico: o primeiro ciclo, que se confunde com a sua formação, quando se atribuiu ao estado a produção exclusiva do Direito; o segundo ciclo ocorreu durante o período da Revolução Francesa, onde se deu a sistematização do direito estatal através de sua codificação. Trata-se, segundo o autor, "de uma etapa fundamental para a estruturação e solidificação da legalidade estatal burguês-capitalista do Ocidente" (Pluralismo Jurídico, p. 45); ao terceiro ciclo atribui-se o período áureo, o seu apogeu, representado principalmente pela dogmática da Escola de Viena, onde se tem Hans Kelsen como principal representante. "A proposta 'científica' de Kelsen descarta o dualismo Estado-Direito, fundindo-os, de tal modo que o Direito é o Estado, e o Estado é o Direito Positivo" (id. ib., p. 50 ss); ao quarto ciclo, situado a partir dos anos 60/70, Wolkmer atribui o "esgotamento de legalidade que sustentou, por mais de três séculos, a modernidade burguês-capitalista" (id. ib., p. 52)

15 BONAVIDES, Paulo. Teoria constitucional da democracia participativa: por um direito constitucional de luta e resistência; por uma nova hermenêutica; por uma repolitização da legitimidade, p. 151. Ao relatar o "colapso do Estado de Direito clássico", cita, o mesmo Autor, o estado nacionalsocialista de Hitler como exemplo, concluindo que "nada mais é preciso acrescentar para mostrar a que ponto inadmissível pôde chegar o positivismo jurídico-formal”(id.ib., pp.151-152). 
tais como abstração, generalidade e unidade, é falha e superficial, pois nunca acompanhou a realidade. Dois fatores levaram a essa situação: a ineficácia do sistema estatal moderno para a resolução de conflitos divergentes daqueles previstos em seu sistema normativo; e a ilegitimidade, por não refletir as necessidades e os interesses de parcelas significativas do povo, no bojo dos conflitos que compõem e traduzem o modelo democrático.

Em muitos países, como é o caso dos países latino-americanos com significativa concentração de população indígena ${ }^{16}$, a ineficiência do estado na dissolução de conflitos e sua ilegitimidade deram-se desde sua implementação, porquanto retratava a vontade de uma minoria exploradora, de interesses apartados tantas vezes da vontade geral do povo. Neste sentido, Raquel Yrigoyen Fajardo, por exemplo, adverte que:

La falta de legitimidad de los sistemas jurídicos en nuestros países está vinculada de modo estructural a la manera en la que se han configurado históricamente el modelo de estado y de juridicidad. El carácter excluyente de dicha configuración es su rasgo más saltante. Expresiones de tal carácter son la falta de canales de participación ciudadana en la gestación normativa, la fuerte presencia de instituciones con poder de influir (como militares y grupos de poder económico), la distancia entre los modelos convencionales de participación política (los partidos políticos, el voto) y la forma de organización y comunicación social cotidiana 
(formas de organización social indígenas y

populares).

II.

Envolta em uma crise de legitimidade e de incompreensão e (in) efetividade constitucional, problema também agravado pela aplicação descontextualizada de tantas teorias importadas ${ }^{17}$, a nova hermenêutica deve ceder a tensões naturais dos novos espaços políticos de atuação, relevando-as quando do "veredicto" interpretativo/aplicativo. $\mathrm{Na}$ falta de diálogo entre estado e sociedade, esta formula meios pelos quais os cidadãos participem na resolução de conflitos emergentes, ainda não administrados pelas normas estatais ${ }^{18}$. Tal constatação torna ainda mais latente uma leitura orgânica "ultra-muros" do texto constitucional, como procedimento inicial de "vitalização" da constituição, tornando-a parte integrante e integralizadora da realidade político-social.

17 A importação de teorias hegemônicas, principalmente de países europeus e dos Estados Unidos da América, como é o caso da teoria hegemônica da democracia, tem sido uma constante nos países periféricos. Essas teorias ignoram a pluridiversidade étnica, as características peculiares de cada região e o envolvimento da população com formas peculiares de interação social, comunitárias, familiares e interestatais. Neste sentido, por não reconhecerem dificuldades peculiares locais de implementação, têm reduzidas a eficácia e conseqüente presteza, na medida permanecem no exame superficial das comunidades dos países ditos periféricos. Nesse sentido, Rocha, atribui à "falta de uma teoria específica sobre o direito e o Estado nesses países (periféricos) (...) a tendência generalizada da doutrina neles circulante de 'universalizar' os modelos de direito e Estado elaborados nos países do primeiro mundo, estendendo-os, indevidamente, ao direito e Estado dos países periféricos” (ROCHA, José de Albuquerque. Estudos sobre o Poder Judiciário, p. 134).

18 Importante relatar que do reconhecimento da inconveniência semântica e política de que toda relação social é relação de ordem legal, ou seja, de que a totalidade das relações sociais é regida e manipulada pelo direito estatal, surge a idéia da pluralidade das relações jurídicas. Denominase "pluralismo jurídico" a posição de reação contra a ineficácia do direito oficial em responder aos problemas trazidos pelas mudanças sociais. Para Wolkmer (Pluralismo jurídico, p. 12) "pluralismo jurídico" significa "a multiplicidade de manifestações ou práticas normativas num mesmo espaço sóciopolítico, interagidas por conflitos ou consensos, podendo ser ou não oficiais e tendo sua razão de ser nas necessidades existenciais, materiais e culturais". Trata-se, portanto, de reconhecer a importância da diversidade e do conflito na percepção e aplicação das normas. 
Curioso é notar que a necessidade de se buscar respostas através de canais não oficiais deu-se, também, pelo descompasso estatal em atender aos "novos direitos" surgidos pela nova "onda" de direitos advinda no século XX. Este "atraso" dá-se, no caso brasileiro, principalmente, em dois âmbitos: na formulação de leis que busquem, sem sucesso, regular os interesses da sociedade, em sua pluralidade de espaços de convívio social; no comprometimento histórico do Judiciário brasileiro com formas elitistas e conservadoras de atuação, desautorizando a universalidade na qual está inserida a Constituição, o que faz com que alguns doutrinadores o reconheçam como um poder fora de época ${ }^{19}$.

Ao caso brasileiro prestam-se as mesmas digressões. Após quase 20 anos de autoritarismo e supressão de direitos, o Brasil deparou-se com uma mutabilidade e, ao mesmo tempo, pluralidade dos sujeitos políticos de decisão, redimensionando as necessidades de uma sociedade que, a cada momento, distanciava-se de uma concepção homogenizadora de liberdades. Ao tempo em que se construía um aparato centralizador de decisão, apelando muitas vezes para modelos de repressão à diversidade sócio-política, promovia-se, em resposta dialética ao modelo autoritário, a formação e fortalecimento de grupos ideológicos libertários contrários ao regime totalitário.

Esses grupos políticos de pressão passaram a externar as mais variadas necessidades, muitos delas impulsionados, como já dito, pela nova "onda" de direitos do século $X X$, sendo reconhecidos como novos sujeitos de participação e transformação sociais. $\mathrm{O}$ clima de otimismo quanto ao retorno das eleições diretas representa apenas um substrato do fortalecimento da consciência cívica em relação aos direitos políticos. Em momento único, a participação do povo, 
antes apenas destinatário ${ }^{20}$ passivo no processo de redemocratização, atribuiu ao momento histórico brasileiro um viés de legitimidade, a ponto de possibilitar à sociedade a materialização do desejo de, negando o período obscuro do autoritarismo iniciado em abril de 1964, fortalecer as bases democráticas através do remodelamento das instituições e a ampliação dos direitos. Esta maneira de direitos fez-se refletir no processo de elaboração da nova Constituição brasileira. "Da declaração de direitos" que outrora encontrara espaço modesto no final dos textos constitucionais, agora recebe novo redimensionamento e novo status, figurando no texto constitucional inicial de 1988 como "direitos e garantias fundamentais" ao novo estado de direito democrático, recebendo, segundo a dogmática jurídica nela implementada, a condição de cláusula pétrea, ou seja, característica de inamovibilidade, salvo ruptura drástica dessa nova ordem.

Esse clima de aparente participação plena não desautoriza afirmar que, assim como no período revolucionário francês há pouco denunciado, a sociedade brasileira foi igualmente vítima de adaptações discursivas quando do exercício constituinte. Nesse sentido são as palavras de Paulo Bonavides e Paes de Andrade ${ }^{21}$ :

Essa participação, todavia, enfraqueceu-se no curso do processo legislativo, de tal forma que as reivindicações constantes das emendas

20 Reportamo-nos à expressão utilizada por Friedrich Müller ao conceituar povo sob a forma de quatro categorias: o povo ativo, o povo como atribuição de legitimidade, o povo enquanto destinatário final e o povo ícone (MÜLLER, Friedrich. Quem é o povo? A questão fundamental da democracia, p. $55 \mathrm{ss}$ ). Não obstante, ciente está o autor de que, mesmo historicamente ter sido uma grande evolução, a participação política, sopesando discursos eufóricos de uma emoção desmedida, não atingiu parte significativa da população brasileira a qual vivia à margem da atuação do Estado-social, reconhecendo, quando muito, a atuação do Estado-violência. 
populares passaram a ser defendidas por alguns constituintes, sem que a sociedade se mantivesse mobilizada para o acompanhamento dos debates e votações. Talvez em razão mesmo dessa ausência, muitas das oportunas sugestões tenham sido marginalizadas, embora exercendo uma determinada influência no corpo legislativo quando cada uma das idéias expostas ou dos temas propostos eram objeto de deliberação.

A positivação desses direitos ${ }^{22}$ traz a lume a necessidade de reconhecimento da pluralidade de demandas sociais colecionadas pela sociedade brasileira durante as suas conquistas. Dessa forma, o reconhecimento dos direitos na esfera constitucional acaba por fortalecê-los diante da realidade que constantemente os nega. Nesse sentido, oportunas as palavras de Paulo Albuquerque ao explicar a expansão dos direitos individuais:

A progressiva perda da fundamentação transcendental do direito não trouxe prejuízos à afirmação dos direitos individuais, pelo contrário: com a positivação do direito surgiram maiores possibilidades de alteração das normas existentes, vindo ao encontro de novas reivindicações geradas pela multiplicação das vontades individuais. Esta, por sua vez, trouxe a constante ameaça de anomia pela 'desilusão' com

22 OLIVEIRA VIANNA. Instituições Políticas Brasileiras: "Tornar jurídicos os valores soberanos da pessoa humana foi a maior luta contra o absolutismo e a opressão, e de bandeira de uma luta que atravessa todo o percurso histórico da civilização e se concretiza quando a sociedade organizada politicamente os reconhece através dos seus dispositivos constitucionais e legais" (id. ib. p. 29). 
a ordem existente, de modo que se pode dizer ser a criação dos direitos individuais uma forma de lidar com sua constante negação prática, pelo reforço do modelo positivo desejado ${ }^{23}$.

Não obstante, para que os direitos não se tornem uma promessa vã, é necessário que as instituições que constituem esse estado de direito acompanhem o processo de diversificação de demandas, para que se possa materializá-los. Nesse diapasão, Plínio de Almeida adverte sobre o perigo do simples reconhecimento e positivação de direitos sem que haja, paralelamente, medidas afirmativas que possam efetivá-los, como se pode observar:

(...)o mero reconhecimento da universalidade de direitos atribuídos a todos não gera necessariamente a aplicação conteudística do pensamento democrático. De forma inversa, pode vir a causar uma visão formal e superficial dos elementos que o compõe, transformando-o em expectativa de ficção científica, longe de produzir efeitos concretizadores de transformações sociais $^{24}$.

Complementa o pensamento Paulo Albuquerque ao reconhecer a diversificação de direitos e a necessidade de se superar o modelo estatal que apenas administra expectativas:

23 AlBUQUERQUE, Paulo A. de Menezes. Evolução dos direitos individuais no estado moderno, p. 149. 
O controle das diversas possibilidades de combinações de direitos e do potencial de conflitos gerados pela impossibilidade de realização de todas as projeções individuais faz com que caiba ao estado não só administrar a convivência concomitante de tais expectativas, mas também atuar preventivamente de modo a sugerir a possibilidade de seu completo atendimento. Diferentemente do estado estamental, em que a lealdade de troca de favores pessoais e a busca de agradar marcavam um tempo social mais lento, os indivíduos-consumidores de hoje têm uma dimensão de fruição de direitos imediata, difícil de ser compensada somente com a noção pessoal e diletória no tempo e espaço de mérito e honra ${ }^{25}$.

Neste diapasão, importante, portanto, a modernização do Poder Judiciário enquanto instituição voltada à interpretação e aplicação de direitos para o fortalecimento do regime democrático atual, no reconhecimento da "tridimensionalidade" da Constituição, longe, assim, de auferir-se legitimidade apenas com a articulação interna dos dispositivos internos para explicitar e procurar solucionar os problemas da não efetivação constitucional. Criado para desempenhar “(...) a função precípua de efetivar e concretizar a ordem jurídica..." 26 , o poder jurisdicional vem atuando à margem das necessidades do estado democrático ${ }^{27}$.

25 AlBUQUERQUE, Paulo A. de Menezes. Evolução dos direitos individuais no estado moderno, p. 152.

26 JUCÁ, Antônio. Reforma do judiciário: algumas reflexões, p. 17.

27 Ao invés de atuar em favor da ideologia democrática, buscando atender a demanda de direitos de modo a satisfazer as necessidades sociais e fortalecer a democracia, o judiciário age, em geral, como 
III.

A Constituição da República de 1988, ao mesmo tempo em que positivou vários direitos, em atendimento à demanda social da época, possibilitou ao intérprete o reconhecimento de novos direitos advindos de futuras demandas, quando da correlação de elementos que orbitam fora da superficialidade do texto constitucional. "No entanto, ainda que se tenha destronado definitivamente a lei escrita e a força semidivina que o positivismo lhe atribuía, este não deixou de exercer sua atração, um canto de sereias aos cultores do Direito" 28 .

A experiência jurídica no Brasil pós-1988, como resposta ao autoritarismo de quase duas décadas, traduz uma tentativa de contemplar a nova realidade com a então perspectiva da chamada "força normativa da Constituição". Mesmo diante de vários esforços, ainda não se conseguiu satisfatoriamente aproximar o texto constitucional com a realidade que os cerca por um motivo bastante óbvio: a Constituição está além das suas amarras internas. E assim deveria ser! Afinal, é preciso que se compreenda, de uma vez por todas, que a progressividade dos textos sinaliza advertência que se estão por realizar. Advertências a exigirem de estado e sociedade - e aqui os juristas e intelectuais acorrem a uma função determinante para que, também, a efetivação dos textos não seja um simples instrumento da retórica de salão - concretas posições sobre as demandas neles contidos. Não é nova esta idéia, e também sobre o caso brasileiro, as

uma espécie de contra-paradigma, posta-se na contramão do processo de evolução político-social. Esse desvirtuamento funcional do judiciário é ainda mais nítido nos países economicamente dependentes, a cujo papel presta-se o Brasil. Isso decorre, em grande parte, da visão dominante que se tem, onde a normatividade constitucional passa a ser concebida como autônoma, ignorando-se que sua essência interna deriva do poder político e ds tensões na sociedade. Cf. MAUS, Ingeborg. Hermann Heller und die Staatsrechtslehre der Bundesrepublik, pp. 200ss. 
palavras de Peter Häberle são alentadoras:

A crítica cínica de déficit da realidade constitucional no Terceiro Mundo distorce a genuína contribuição dos pequenos, bem como suas possibilidades de recuperar o futuro. (...) Os textos progressistas permanecem então como provocadora advertência a todos nós. E, não devemos esquecer, todos os textos clássicos foram, em parte, utopias ${ }^{29}$.

Dentre as tentativas teóricas destaco a teoria neoconstitucionalista ${ }^{30}$ como modelo incursivo da realidade constitucional atual. Emergente do campo do dogmatismo jurídico, a também denominada como teoria neopositivista concentra seus esforços na inserção normatizadora dos princípios constitucionais como instrumento basilar para a materialização e conseqüente valorização do texto constitucional. Apresenta, pois, a constituição como um sistema integrado por regras e princípios, em cuja interpretação conjunta resultaria a aplicação das normas constitucionais.

A percepção de um universo de relações interpessoais

29

HÄBERLE, Peter, Die Entwicklungsländer im Prozeß der Textstufendifferenzierung des Verfassungsrechts, p. 265/266. No original: „Der zynische oder besserwisserisch spöttische Hinweis auf „Defizite“ der Verfassungswirklichkeit in Übersee verkennt die genuine Leistung des „,kleinen“" Entwicklungslandes ebenso wie dessen Möglichkeit des „Aufholens “ in der Zukunft“. Häberle erkennt auch die Faszination, die von einer einmal erreichten Textstufendifferenzierung weltweit ausgeht. „Der fortgeschrittene Text bleibt eine provozierende Mahnung an alle. Und auch die heute klassischen Textelemente des Verfassungsstaates waren einmal zum Teil Utopie“.

30 Alguns estudiosos dedicam-se com afinco ao estudo do neoconstitucionalismo. O que se percebe, entre eles, é a prevalência de um idealismo desconectado das tensões econômicas, políticas e sociais. Embora não sejam ignoradas pelo neoconstitucionalismo digressões nesta direção, não ocupam elas o tema central de suas preocupações para a efetivação constitucional. Esta identificação pode ser muito bem resmida por POZZOLO, Susanna: Neoconstitucionalismo e positivismo jurídico, pp. 79ss. 
travadas em sociedade revela a existência de necessidades de seus membros. De outro lado, a disparidade dessas necessidades, com toda a contingência que as cercam, é atenuada pela idéia de que se relacionam com a constituição e transformação de direitos, objeto de conhecimentos jurídicos informais, ligados à vivência imediata, e formais, dependentes de organizações ou processos específicos de sua tematização. Formam-se assim diversos canais de comunicação, dada as possibilidades de mútua influência entre os conhecimentos de um tipo e de outro, determinando a produção e aplicação concreta do Direito.

Chamam a atenção neste ponto propostas de reflexão sobre o direito que, exatamente por atenuarem tensões de natureza mais abrangente na perspectiva de se formarem núcleos solucionadores de problemas maiores em nível localizado. Recorremos aqui às ponderações formuladas a partir do comunitarismo, aplicado numa visão conflitante com o universalismo, mas que, de maneira esdrúxula, procuram, ao mesmo tempo conciliar dois âmbitos que, para o início da mesma análise, são considerados como opostos. Em outras palavras, reconhece-se os conflitos dos problemas entre visões "comunitaristas" e universaliats, mas a proposição de solução procura conciliá-los na tentativa de prevalência do "comunitarismo" sobre o "universalismo". O que resta indagar é como elementos que se têm como conflitantes podem, a partir do decisionismo, ser conciliados 
sem a explícita mediação da política.

Um exemplo de publicação nada vulgar neste sentido é a obra organizada por Cecilia Caballero Lois ${ }^{31}$, com um instigante texto de Guilherme Soares ${ }^{32}$.O ponto de partida deste autor não poderia ser mais feliz: o julgamento pelo Supremo Tribunal Federal do caso conhecido como "anti-semitismo" ${ }^{33}$.Embora seja refinada a compreensão sobre a neutralidade política e sua função integradora de valores numa sociedade.plural, a ponto de se "[permitir] fundar um ideal publicamente compartilhável" ${ }^{34}$, não nos parece que o cerne da problemática para o sucesso ou insucesso do, no caso, art. $5^{\circ}$, XLII da Constituição Federal, resida na idéia de que “(...) a neutralidade é um tema sob o qual indivíduos lingüisticamente competentes devem conversar, sobretudo quando o resultado de sua controvérsia define o sentido do diploma normativo mais fundamental de uma comunidade política"35.

Isso se dá em virtude da forte dose de idealismo liberal presente na visão de que entre "indivíduos lingüisticamente competentes" estariam todos os brasileiros e de que a "definição do sentido normativo" da Constituição pudesse ser percebida apenas a partir deste limitado universo de participação, isto é, dos integrantes do Supremo Tribunal Federal e partes envolvidas no caso concreto. Ora, a democracia brasileira, como de resto aquela do mundo de tradição ocidental cristã, cai bem na definição de Alex Demirović de que é uma democracia de classe, mas que se reivindica como

\footnotetext{
31 Cf. Justiça e Democracia - Entre o universalismo e o comunitarismo. Ed. Landy, SP, 2005.

32 Na obra citada na nota anterior, o ensaio de Guilherme Soares é: Neutralidade e comunidade no diálogo liberal: em torno do pensamento de Bruce Ackerman, pp. 51-85.

HC 82424-2/RS, Rel. Min. Moreira Alves.

34 SOARES, Guilherme. Neutralidade e comunidade no diálogo liberal: em torno do pensamento de Bruce Ackerman, p. 84. 
se de todos fosse ${ }^{36}$. Este aspecto fundante do sistema democráticoconstitucional brasileiro não permite que, em tais condições, agentes de participação lingüística, por si só, resolvam problemas de tamanha complexidade, tampouco assegura que no decisionismo judicial que, por meio da neutralidade política dos julgamentos constitucionais a se guiarem pela avaliação da qualidade do universalismo brasileiro e de sua situação para garantir uma igualdade de todos, impedindo o favorecimento de determinadas referências resida a chance de nosso sucesso constitucional, bem como dos direitos e garantias que têm diferenciado nosso constitucionalismo das últimas décadas.

Esta visão aproxima-se, sobretudo, do idealismo liberal aliás, os bons autores da coletânea organizada por Cecília C. Lois não teriam como negar o viés de inclinação liberal da chamada moderna teoria da justiça, com base nos mestres estrangeiros escolhidos pelo fato de pretender uma neutralidade constitucional e política normativa que a própria tensão constitucional não possui e é, ao contrário, possuidora de um compromisso entre distintos, como sugere claramente Hermann Heller. E o fato de se ter no Brasil uma constituição dirigente não afasta somente a possibilidade de apreensão dos preceitos liberais de comunitarismo e universalismo, que formam o neoconstitucionalismo. Há uma natureza particular de qualquer sistema político organizado mesmo em razão de sua experiência préconstitucional concreta. Portanto, está-se diante de um problema de poder constituinte de origem democrática, o que não parece ter sido assimilado pela tentativa da "moderna teoria da justiça".

36

Estas são as palavras do citado Autor ( DEMIROVIĆ, Alex. Bürgerliche Demokratie Ein historischer Kompromiß?, p. 503): “Correspondentemente, não critica Poulantzas o fato de que o Estado burguês não é um Estado neutro enquanto é ele na verdade um Estado de classes. Segundo seu pensamento, a contradição está localizada na explicação de que o Estado se apresenta como um Estado de classes da burguesia, incluindo ao mesmo tempo todas as classes. No original: „Dementschprechend kritisiert Poulantzas nicht, daß der bürgerliche Staat sich als neutralaer Staat gibt, während er in der Wirklichkeit Klassentaat wäre. Seiner Meinung nach ist der Widerspruch der, daß der Staat sich als Klassenstaat der Bourgeoisie präsentiert, gelichzeitig aber das ganze Volk zu dieser Klasse rechnet". 
$\mathrm{Na}$ análise sobre neoconstitucionalismo parece possível depreender-se o quê há de muito tempo se sabe: não é a autonomia do universo normativo que resgatará a constituição, sua efetivação ou o próprio constitucionalismo, principalmente o constitucionalismo dirigente brasileiro. Não há como se crer que a única esperança é a constituição, sem que esta esperança esteja articulada com outros parâmetros.

Avelãs Nunes $^{37}$ deixa evidente, em lúcidas idéias, o significado da inclusão, para a análise da economia política, dos elementos exteriores ao mercado e às mercadorias, que, até o século XIX, não adentravam no universo dos economistas, dos juristas, dos políticos e de todos os setores da sociedade. Isso porque os grandes economistas políticos clássicos recusavam-se a ir além dos mercados e das mercadorias para solucionar também os problemas econômicos, políticos e sociais das sociedades, a fim de proporem realistas soluções para a miséria da maior parte da população, da deficiência da representação política e da instável e traiçoeira política internacional das então grandes potências econômicas da fase tardia da Revolução Industrial. A objetividade do acúmulo histórico comprovou que o enfrentamento de algumas destas grandes tarefas não se resolveu somente com a crença na autonomia dos mercados e das mercadorias.

De forma semelhante, a crença do neoconstitucionalismo de que a interpretação constitucional com base no normativismo autônomo ou partindo dos juízos que seus aplicadores possuem tudo pode resolver ou mesmo emprestar à constituição um prestígio de efetivação e de validade que ela jamais teria tido, pode ser caracterizada como a fria tentativa de compreender apenas "o mercado e as mercadorias" para definir a economia política, negando 
vitalidade aos elementos que objetivamente o formam e com elas interagem em seu percurso histórico-político. Não se conhece somente os resultados desta operação do neoconstitucionalismo em campos distintos do saber, como o da economia aqui apontado. No âmbito do direito constitucional, existe registro desta experiência, com o desgaste da própria Constituição Federal, quando se socorre de elementos meramente normativos na tentativa de manutenção, empurrando, por exemplo, movimentos sociais para a ilegalidade, que seria, na verdade uma legalidade maior "(...) o cumprimento efetivo da Constituição da República"38.

Não há nada de estranho em se constatar contradições nas constituições dirigentes ou sociais. Este modelo de constitucionalismo surgiu nas sociedades exatamente para alteração do modo econômico, político e social. Assim, é difícil imaginar que se possa construir um consenso permanente sobre pontos extremamente delicados, como é o caso da questão da propriedade na Constituição Federal, que ainda resta impregnado de amarras jurídicos e teóricas a inviabilizarem um desfecho em favor da direção que claramente aponta a constituição social, como destaca Gilberto Bercovici:

Será justamente na ordem econômica da Constituição que os seis críticos encontrarão as >contradições< e os chamados >compromissos dilatórios $<$. E isso desde o debate da Constituição de Weimar. Já em sua Teoria da Constituição (Verfassungslehre), de 1928, Carl Schmitt afirmava que essa Constituição, embora contivesse as decisões políticas fundamentais sobre a forma 
de existência política concreta do povo alemão, possuía em seu texto inúmeros compromissos e obscuridades que não levavam a decisão alguma, mas, pelo contrário, cuja decisão o havia sido $\operatorname{adiada}^{39}$.

Uma vez dotada de compromissos políticos - e, para o caso brasileiro, em grande parte das vezes imobilizadores da ação do estado - não há como se pretender que aplicadores optem por uma posição de neutralidade frente aos valores por elas escolhidos. Aqui, julgadores e legisladores estão vinculados aos valores econômicos e sociais desta Constituição, vendo-se, portanto, na obrigatoriedade de decidirem neste sentido, não deixando dúvidas quanto a este posicionamento. Oferece substância a esta firmação a tese de que o momento do debate foi o instante constituinte, superado durante o processo de elaboração, que para a Constituição de 1988 não deixa dúvidas quanto á sua legitimidade democrática formal.

Não parece difícil que se entenda a razão de as "teorias modernas da justiça" a alimentarem o neoconstitucionalismo tenham sua reflexão na bibliografia de reconhecidas autoridades intelectuais dos Estados Unidos da América, como Bruce Ackerman, Ronald Dworkin e John Rawls. Afinal, a Constituição Americana nada tem de dirigente e o tema da intervenção do estado na economia, ou mesmo a prevalência sobre o indivíduo ainda representam verdadeiros mitos para a jurisprudência americana. Correto em se cogitar da possibilidade de aplicação de tais teorias nos Estados Unidos ou naquelas sociedades de consolidada tradição liberal. Mesmo os liberais que servem de base para o neoconstitucionalismo, nessa 
hipótese, confirmam que tais teorias se mostram bem sucedidas nestas sociedades porque tais teorias consideram a formação econômica e política já existente e esta formação é, claro, liberal. Após constatarem este detalhe, é possível teorizar sobre comunitarismo, universalismo, decisionismo etc.

Não surpreende que este detalhe passe desapercebido pelos que pelejam em favor da recepção no Brasil - e no constitucionalismo brasileiro - das teorias liberais a instruírem o neoconstitucionalismo: já que ante este olhar sempre se busca desesperadamente o "progresso", só nos resta valer-se de Marleau-Ponty: "Transformar caminhada em progresso é elaboração ideológica das elites" ${ }^{40}$.

Se se quer, neste contexto, enfrentar a crítica conservadora, não há como se deixar de trabalhar de forma realista e em conformidade com o dirigismo da Constituição Federal a problemática da esperança, enquanto potencial emancipatório da consciência de uma sociedade. Aqui, a referência ao "princípio esperança", formulado por Ernst Bloch em 1955, vem a oferecer interessante visão analítica.

Ernst Bloch publicou, na extinta República Democrática Alemã, seu trabalho de mais 1.500 páginas, "O Princípio Esperança"41, obra que o fez membro da Academia de Ciências de Berlim ${ }^{42}$. A esperança concebida por Bloch trata da energia humana traduzida pela paixão do êxito sobre o fracasso. A esperança, nesta vertente, nada tem de idealista, passando a significar o querer como superação do desejo, na medida em que aquele concretiza a pulsão pela vida e pelo fazer, enquanto este possui em seu núcleo a passividade (ou mesmo a angústia do arrependimento):

$40 \quad$ Apud DUPAS, Gilberto: O mito do progresso, p. 7.

41 Das Prinzip Hoffnung, no original, publicado em 1959, na República Federal da Alemanha, pela editora Suhrkamp, Frankfurt/M.

42 CALDWELL, Peter C.: Dictatorship, State Planning and Social Theory in the German Democratic Republic, p. 122. 
Porém, por mais intenso que seja, neste ponto o desejar se diferencia do querer propriamente dito por seu modo passivo, ainda parecido com o ansiar. No desejar não há nada de trabalho ou atividade. Em contrapartida, todo querer é um querer-fazer. (...) Aquele que quer, ao contrário, já estabeleceu uma preferência: sabe o que prefere, a escolha ficou para trás., (...) O querer, ao contrário, é necessariamente um avançar ativo rumo a esse alvo, dirige-se para fora, tem de se medir unicamente com coisas realmente dadas ${ }^{43}$.

A energia a movimentar a esperança é, desta forma, o querer, a ação, sempre para frente, em direção aos objetivos que se impõem perante o homem em sociedade. Daí deriva a crítica de Bloch a Hegel e a Freud. Para Bloch, o primeiro olha para o passado, a fim de imobilizar o presente - e o futuro - na forma ideal do que é: “aquilo que é racional, isto é o real; e o quê é real, este é o racional" 44 . Freud representa, para Bloch, o pensamento do presente, sem igualmente considerar o futuro. O futuro, o infinito vir-a-ser é de Marx, que conclamou a todos os homens do mundo numa perspectiva universalista. Pois desta forma é que devem ser compreendidos, por exemplo, os direitos fundamentais, numa possibilidade emancipatória. Liberdade de expressão de pensamento, de reunião, direito de greve não deveriam ser objetos de garantia. Não se trata, sob esta ótica e para Bloch, sobre direito "de" alguma coisa, mas de

43 BLOCH, Ernst. O Princípio Esperança, pp. 50/51.

44 HEGEL, G. W. F. Gundlinien der Philosophie des Rechts, p. 14. No orginal: „Was vernünfitg ist, das ist wirklich; was wirklich ist, das ist vernünftig“. 
direito "para", "em direção" a alguma coisa. Assim é que a "liberdade final" seria uma liberdade que não se oporia à ordem, mas seria dela parte, "uma ordem concebida numa sociedade pura e simplesmente não coercitiva, de uma estrutura não antagônica" 45 .

A Constituição Federal de 1988 é também um documento da esperança, o quê se deixa provar pelo "querer-fazer" de suas determinações. É lugar-comum a afirmação de que nosso texto constitucional não simboliza simplesmente um "catálogo" de boas intenções. Portanto, não seria, na linguagem de Ernst Bloch, um pueril desejar, alimentado pela angústia da imobilização. O interessante é que os discursos contrários à Constituição, de base normativista e conscientemente idealistas, não cansa de repetir o espontaneísmo de que "a Constituição foi aviltada", ou de que nada se fez no País nos últimos vinte anos, ou ainda apelar para a sofisticada "morte da constituição dirigente". Com este status quo discursivo liquidase tanto o potencial do "querer-fazer" da Constituição, como ainda ilude-se sobre quem veicula tal discurso, na medida em que este ator intelectual ou político aparecerá, geralmente, como venerável e velho sábio, crítico do marasmo e de ineficiência da Constituição da República. Assim, "mudamos alguma coisa para que nada mude", como está disseminada esta idéia em parte significativa da esperta cultura política brasileira!

Assimilar a ordem constitucional brasileira de 1988 aos dias atuais não consiste num fácil exercício de retórica, mas num desafio de ter em mente de que sua efetivação dependerá da sociedade brasileira e de seus esforços. Excluir a sociedade desta tarefa, relegando-a a atores intelectuais e políticos somente servirá ao deleite dos que sempre mandaram e mantiveram seus privilégios, 
numa sociedade herdeira não somente da escravidão; mas herdeira de uma perene cultura da escravidão. A esperança que se substitui ao fracasso à implementação do texto constitucional brasileiro será, a priori, a aceitação de que este texto constitucional veio para mudar. Aplicar critérios interpretativos da hermenêutica do século XIX, recorrer a antigos paradigmas do direito privado como fórmula de resolução dos conflitos numa sociedade de extrema desigualdade com a brasileira coincide com o cancelamento da esperança constitucional. As dificuldades da implementação constitucional não decorrem da distância entre seu texto e a objetiva realidade brasileira. Decorrem bem mais do comportamento dos atores intelectuais e políticos em bloquear suas inovações estruturais, seja no plano nacional, seja no internacional. Aqui, o argumento da "morte da constituição dirigente", surgido nos últimos cinco anos, ganha força toda especial contra a constituição da realista esperança.

Por fim, se não podemos dizer que o neoconstitucionalismo é culpado das marchas e contra-marchas da Constituição da República, não temos como deixar de qualificá-lo como forte colaborador do discurso conservador que busca desacreditá-la, não por força de sua inefetividade baseada em tormentos econômicos, políticos e sociais realisticamente não compreendidos e assim enfrentados, mas pela convicção das correntes neoconstitucionalista de que a tarefa de efetivação constitucional é de intérpretes, lingüistas e de ponderações. Tal qual a proposta radical da democracia, esta tarefa é de todos os atores presentes nos conflitos sociais. Afinal, democracia nada mais é do que viver com conflitos a exigirem cada vez mais dos estados e das sociedades. 


\section{Referências Bibliográficas}

ALBUQUERQUE, Paulo Antonio de Menezes. ALMEIDA, Plínio Régis Baima de. "Metamorfoses" da democracia e controle normativo da Constituição. In: Revista da Procuradoria Geral do Município de Fortaleza. v. 12. Fortaleza: Procuradoria Geral do município de Fortaleza, 2004. p. 95 - 108.

ALBUQUERQUE, Paulo Antonio de Menezes. Evolução dos direitos individuais no estado moderno. Revista Pensar. v. 6, , Fev. Fortaleza: Universidade de Fortaleza, n. ${ }^{\circ}$ 6, 2001. p. 145 - 154.

ALMEIDA, Plínio Régis Baima de. O conceito de povo cidadão. In: A cidadania em debate: estudos sobre a efetivação do direito na atualidade. Lília Maia de Moraes Sales (org). Fortaleza: Universidade de Fortaleza, 2005. p. 221 - 232.

ANDRADE, Antônio Paes de. BONAVIDES, Paulo. História Constitucional do Brasil. Brasília: Paz e Terra, 1989.

BERCOVICI, Gilberto. Constituição Econômica e Desenvolvimento. Uma leitura a partir d Constituição de 1988. São Paulo: Malheiros Editores, 2005.

BLOCH, Ernst. O Princípio Esperança. Rio de Janeiro: Ed. Contraponto/ Ed. da Universidade Estadual do Rio de Janeiro, v. 1, 2005.

CALDWELL, Peter C. Dictatorship, State Planning and Social Theory in the German Democratic Republic. Cambridge: Cambridge University 
Press, 2003.

BONAVIDES, Paulo. Teoria constitucional da democracia participativa:por um direito constitucional de luta e resistência; por uma nova hermenêutica; por uma repolitização da legitimidade. São Paulo: Malheiros, 2001.

COSTA, Nelson Nery. Teoria e Realidade da Desobediência Civil. $2^{\mathrm{a}}$ Ed. Rio de Janeiro: Forense, 2000.

DALLARI, Dalmo de Abreu. O Poder dos Juízes. $2^{\mathrm{a}}$ ed. São Paulo: Saraiva, 2002.

DEMIROVIĆ, Alex. Bürgerliche Demokratie-Ein historischer Kompromiß? $\mathrm{Zu}$ einigen Problemen der Staatstheorie Nicos Poulantyzas' In: Archiv für Recht und Sozialphilosophie, vol. 1987, LXXIII/Heft 4, 4. Quartal, Franz Steiner Verlag, Wiesbaden/Stuttgart, pp. 495-518.

DUPAS, Gilberto. O mito do progresso. Ed. Unesp. São Paulo, 2006.

FAJARDO, Raquel Yrigoyen. Justicia y pluralismo legal en Guatemala. Disponível em: http://www.unb.br/ics/dan/geri/Textos/ yrigoyen.htm. Acesso em 13 de julho de 2005.

HÄBERLE, Peter: Die Entwicklungsländer im Prozeß der Textdifferenzierung des Verfassungsrechts. In: Verfassung und Recht in Übersee, 23. Jahrgang, 3. Quartal 1990, hrsg. von Brun-Otto Bryde und Philip Kunig. Nomos Verlagsgesellschaft. Baden-Baden, 1990, pp. 225-296.

HEGEL, Georg Wilhelm Friedrich. Grundlinien der Philosophie des 
Rech. In: G.W.F. Hegel; Hauptwerke in sechs Bänden. Darmstadt: Wissenschaftliche Buch-gesellschaft, Bd. 5, 1995.

GOYARD-FABRE, Simone. Princípios filosóficos do direito político moderno. Trad. Irene A. Paternot., São Paulo: Martins Fontes, 2002

GRAU, Eros Roberto. Realismo e utopia constitucional. In: Diálogos constitucionais: direito, neoliberalismo e desenvolvimento em países periféricos. Jacinto Nelson de Miranda Coutinho e Martônio Mont'Alverne Barreto Lima (orgs.). Rio de Janeiro: Renovar, 2006, pp. 133-144.

JUCÁ, Francisco Pedro. Reforma do judiciário: algumas reflexões. In: Reforma do Judiciário. TAVARES, André Ramos, LENZA, Pedro, ALANÓN, Pietro de Jesús Lora. (Org.) São Paulo: Método, 2005. pp. $13-22$.

KELSEN, Hans. Teoria pura do direito. Martins Fontes, São Paulo, 2004.

LERCHE, Peter. Übermaß und Verfassungsrecht: Zur Bildung des Gesetzgebers and die Grundsätye der Vehältnissmäßigkeit und der Erförderlichkeit. 2. Auflage. Goldbach: Keip Verlag, 1999.

LOSURDO, Domenico. Democracia ou Bonapartismo. Ed. UFRJ/ UNESP, RJ., 2004.

MAUS, Ingeborg. Hermann Heller und die Staastrechtslehre der Bundesrpublik. In: Staatslehre in der Weimarer Republik. MÜLLER; Christoph. STAFF, Ilse (Hergs). Suhrkamp Taschenbuch, erste Auflage, Frankfurt/M., 1985, pp. 194-220. 
MÜLLER, Friedrich. Quem é o Povo? A Questão Fundamental da Democracia. $2^{\text {a }}$ Ed. São Paulo: Max Limonad, 2000.

NUNES, António José Avelãs. Ricardo e Marx: continuidade e rotura. In: Boletim de Ciências Eeconómicas, XLIX. Coimbra. 2006, pp. 1-82.

PIÇARRA, Nuno. A separação dos poderes como doutrina e princípio constitucional: um contributo para o estudo das suas origens e evolução. Coimbra: Coimbra, 1989.

POZZOLO, Susanna. DUARTE, Écio Oto Ramos. Neoconstitucionalismo e positivismo jurídico - as faces da teoria do direito em tempos de interpretação moral da Constituição. São Paulo, Landy, 2006.

ROCHA, José de Albuquerque. Estudos sobre o Poder Judiciário. São Paulo: Malheiros, 1995.

SCHOPENHAUER, Arthur. A arte de escrever. Trad. Pedro Süssekind. Porto Alegre: L\&OM, 2006.

SOARES, Guilherme: Neutralidade e comunidade no diálogo liberal: em torno do pensamento de Bruce Ackerman. In: Justiça e Democracia - Entre o universalismo e o comunitarismo. A contribuição de Rawls, Dworkin, Ackerman, Raz, Walzer e Habermas para a moderna teoria da justiça. LOIS, Cecília Caballero (org.), São Paulo: Ed. Landy, 2005.pp. 51-85.

STAFF, Ilse. Staatslehre in der Weimarer Republik. In: Staatslehre in der Weimarer Republik. MÜLLER; Christoph. STAFF, Ilse (Hergs). 
Suhrkamp Taschenbuch, erste Auflage, Frankfurt/M., 1985, p. 7-23.

TAVARES, André Ramos. Abertura epistêmica do direito constitucional. In: Democracia, direito e politica: estudos internacionais em homenagem a Friedrich Müller. ALBUQUERQUE, Paulo Antonio de Menezes. LIMA, Martônio Mont'Alverne Barreto (Org.). Florianópolis: Conceito Editorial, 2006. p. 97 - 112.

VIANNA, Francisco José de Oliveira. Instituições políticas brasileiras. São Paulo: Itatiaia, 1987.

WOLKMER, Antônio Carlos. Pluralismo jurídico: fundamentos de uma nova cultura no Direito. São Paulo: Alfa Omega, 1994. 